\title{
GPPS-CH-2020-0173
}

\section{IMPROVEMENT OF CORNER SEPARATION PREDICTION USING AN EXPLICIT NON-LINEAR RANS CLOSURE}

\author{
Wei Sun \\ Whittle Laboratory \\ University of Cambridge \\ ws344@cam.ac.uk \\ Cambridge, CB3 ODY, England
}

\author{
Liping Xu \\ Whittle Laboratory \\ University of Cambridge \\ Ipx1@cam.ac.uk \\ Cambridge, CB3 ODY, England
}

\begin{abstract}
In this paper, an investigation into the effect of explicit non-linear turbulence modelling on anisotropic turbulence flows is presented. Such anisotropic turbulence flows are typified in the corner separations in turbomachinery. The commonly used Reynolds-Averaged Navier-Stokes (RANS) turbulence closures, in which the Reynolds stress tensor is modelled by the Boussinesq (linear) constitutive relation with the mean strain-rate tensor, often struggle to predict corner separation with reasonable accuracy. The physical reason for this modelling deficiency is partially attributable to the Boussinesq hypothesis which does not count for the turbulence anisotropy, whilst in a corner separation, the flow is subject to three-dimensional (3D) shear and the effects due to turbulence anisotropy may not be ignored. In light of this, an explicit non-linear Reynolds stress-strain constitutive relation developed by Menter et al. is adopted as a modification of the Reynolds-stress anisotropy. Coupled with the Menter's hybrid $k-\omega / k-\varepsilon$ turbulence model, this nonlinear constitutive relation gives significantly improved predictions for the corner separation flows within a compressor cascade, at both the design and off-design flow conditions. The mean flow field are studied to further investigate the physical reasons for these improvements, highlighting its potential for the widespread applications in the corner separation prediction.
\end{abstract}

\section{INTRODUCTION}

Corner separation is one kind of the 3D separated flows that is commonly observed at the junction of the endwall and blade suction surface within axial compressors. At off-design flow conditions, this separation can appear to be large and localized, which can contribute significantly to the passage blockage. This places a limit on the loading and static pressure rise achievable by the compressor (Gbadebo et al., 2005). Furthermore, once flow separates, the mixing within the separation region, and the mixing of the separated flow with the main passage flow may lead to a considerable stagnation pressure loss and thus reduction in the compressor efficiency (Dong et al., 1986). Therefore, it is necessary for Computational Fluid Dynamics (CFD) to predict corner separation and its consequences with good confidence, in order for it to be used as a reliable design and analysis tool.

Despite the recent advances in the scale resolving CFD simulation capabilities, RANS is still widely used in the industrial simulations, and will remain in high demand at least until the mid-21 ${ }^{\text {st }}$ century (Spalart, 2015). This is largely because of its cost-effectiveness, numerical robustness, and relatively easy of use. However, several eddy viscosity based RANS closure models that are commonly used in industry, such as Spalart-Allmaras (SA) model (Spalart and Allmaras, 1992) and Menter's hybrid $k-\omega / k-\varepsilon$ model (Menter, 1994, 2003), were found to over-predict the extent of corner separation (Liu et al., 2012; Monier et al., 2016). One of the sources of modelling uncertainties occurs in the Boussinesq constitutive relation, which was introduced for the Reynolds-stress closure in the mean transport equations. This constitutive relation implies the instantaneous values of the Reynolds stress tensor be linearly related to the local mean strain-rate tensor via the eddy viscosity $v_{t}$ (Boussinesq, 1903). Herein $v_{t}$ is a scalar variable and this constitutive relation between the fluctuating and mean fields is hypothesized to be the same in all directions (Mishra et al., 2017). For simple shear flows where the principle shear stress plays a dominant role in the mean momentum transport equations, the Boussinesq constitutive relation may still give fairly close approximations for the mean flow field, even though the predictions for the Reynolds normal stresses are not satisfactory. That is, the Reynolds normal stresses in all three directions are set to be equal, i.e. $\overline{(u)^{2}}=\overline{\left(v^{\prime}\right)^{2}}=\overline{\left(w^{\prime}\right)^{2}}$. However, for complex flows where turbulence could be highly anisotropic, this will force an isotropic distribution of 
turbulence kinetic energy (TKE) from different components of fluctuation velocities, which is non-physical in nature.

To reduce the modelling uncertainties for corner flows, there have been a number of studies focusing on the mathematical formulation of the non-linear stress-strain relationship for more turbulence anisotropic effects to be realistically modelled, e.g., Pope (1975), Hanjalić et al. (1976), Gatski and Speziale (1993), Spalart (2000), Hellsten and Wallin (2009). As explained by Gatski and Speziale (1993), the secondary flow of the second kind, as observed around corners, acts as one of the main physical mechanisms to determine the location of the corner separation onset. In other words, it is observed that the secondary flow driven by the anisotropy in the Reynolds normal stresses extracts momentum from the main passage flow into the corner. This leads to the corner flow being more resistant to the adverse pressure gradient, and thus delays the separation onset. The secondary flow of the second kind can only be captured via the incorporation of higher-order terms in the stress-strain relation. All turbulence closures that are based on the linear stress-strain relationship are intrinsically incapable to predict this flow phenomenon.

In the current paper, the primary goal is to investigate the predictive capabilities of a recently developed non-linear stress-strain relation (Menter et al., 2018) for the secondary flows in corners. This is an explicit constitutive relation which is capable of reproducing turbulence anisotropy in the normal stresses without a large penalty on simplicity, cost, and robustness. Coupled with the Menter's hybrid $k-\omega / k$ - $\varepsilon$ turbulence model, this non-linear constitutive relation is validated for the corner separation flows at varying inflow conditions. The mean velocity field and the turbulent flow field around the corner are then investigated to demonstrate its effectiveness on suppressing the premature separation from the corners.

\section{MODEL FORMULATION}

\section{The Explicit Quadratic Constitutive Relation}

This non-linear stress-strain relation (Menter et al., 2018) is formulated as an explicit extension over the Boussinesq constitutive relation by including the various forms of the scalar product of second-order tensors, i.e. the mean strain-rate tensor and the vorticity tensor, which is shown as below:

$$
\tau_{i j}=\tau_{i j}^{E V}-C_{\text {CORNER }} \frac{1.2 v_{t}}{\max \left(0.3 \omega, \sqrt{0.5\left(S^{2}+\Omega^{2}\right)}\right)}\left(S_{i k} \Omega_{k j}-\Omega_{i k} S_{k j}\right)
$$

with

$$
\begin{gathered}
\tau_{i j}^{E V}=-\frac{2}{3} k \delta_{i j}+2 v_{t} S_{i j} \\
S_{i j}=\frac{1}{2}\left(\frac{\partial u_{i}}{\partial x_{j}}+\frac{\partial u_{j}}{\partial x_{i}}\right) \\
\Omega_{i j}=\frac{1}{2}\left(\frac{\partial u_{i}}{\partial x_{j}}-\frac{\partial u_{j}}{\partial x_{i}}\right)
\end{gathered}
$$

$$
\begin{gathered}
S=\sqrt{2 S_{i j} S_{i j}} \\
\Omega=\sqrt{2 \Omega_{i j} \Omega_{i j}}
\end{gathered}
$$

where $\tau_{i j}^{E V}, S$, and $\Omega$ denote the Reynolds stress tensor computed using the Boussinesq hypothesis, the mean strainrate magnitude, and the vorticity magnitude, respectively. $C_{\text {CORNER }}$ is an adjustable parameter that controls the strength of the turbulence anisotropy, with a recommended range between 0 and 1.5 and the default value as 1.0 (Menter et al., 2018). As equation (1) shows, the proposed constitutive relation was designed in combination with the $k-\omega$ type models to close the RANS governing equations. And here the Menter's hybrid $k-\omega / k-\varepsilon$ model is adopted, which avoids the model sensitivities to freestream turbulent variables (Wilcox, 1988).

\section{The Menter's Hybrid $k-\omega / k-\varepsilon$ Model from 2003 (BSL-2003)}

The Menter's hybrid $k-\omega / k-\varepsilon$ model along with the eddy-viscosity definition read as follows (Menter, 2003):

$$
\begin{aligned}
\frac{\partial(k)}{\partial t}+\frac{\partial\left(u_{j} k\right)}{\partial x_{j}} & ={\widetilde{P_{k}}}^{-} \beta^{*} \omega k+\frac{\partial}{\partial x_{j}}\left[\left(v+\sigma_{k} v_{t}\right) \frac{\partial k}{\partial x_{j}}\right] \\
\frac{\partial(\omega)}{\partial t}+\frac{\partial\left(u_{j} \omega\right)}{\partial x_{j}} & =\frac{\gamma}{v_{t}} \widetilde{P_{k}}-\beta \omega^{2}+\frac{\partial}{\partial x_{j}}\left[\left(v+\sigma_{\omega} v_{t}\right) \frac{\partial \omega}{\partial x_{j}}\right] \\
& +2\left(1-F_{1}\right) \frac{\sigma_{\omega 2}}{\omega} \frac{\partial k}{\partial x_{j}} \frac{\partial \omega}{\partial x_{j}}
\end{aligned}
$$

where the production of TKE $\widetilde{P_{k}}$ is defined as

$$
\widetilde{P_{k}}=\min \left(\tau_{i j} \frac{\partial u_{i}}{\partial x_{j}}, 10 \beta^{*} \omega k\right)
$$

The turbulent eddy viscosity is computed as:

$$
v_{t}=\frac{k}{\omega}
$$

\section{COMPUTATIONAL DETAILS}

\section{Flow Solver}

In the current research, all validation cases are conducted using the ANSYS FLUENT solver, in which the above explicit quadratic constitutive relation is activated and modified via the user-defined macros. The numerical scheme adopted is the pressure-based pressure-velocity segregated algorithm, with the second-order upwind scheme used for the discretization of convection terms in all transport equations. For pressure interpolation the second-order scheme is adopted, and the gradients are approximated with the use of node-based Green-Gauss method.

\section{The LMFA-NACA65 Cascade}

A linear compressor cascade on which was experimentally investigated by Ma (2011) and Zambonini (2016) at Laboratoire de Mécanique des Fluides et d'Acoustique (LMFA) is used here for the numerical 
investigation of corner separation. The LMFA-NACA65 compressor cascade consists of 13 NACA65-009 blades mounted at the end of an open circuit subsonic wind tunnel (Ma, 2011). In the experiment, two strips of sandpaper with $3.0 \mathrm{~mm}$ width by $0.3 \mathrm{~mm}$ thickness were stuck at an arc length of $6 \mathrm{~mm}$ from the leading edge of both the blade suction and pressure surfaces. The aim is to trigger the laminar-toturbulent transition process at the early stage of the blade surface boundary layer development, whereby removing the impact of boundary-layer transition on the downstream corner separation. This contributes to reducing the difficulties of RANS simulations, as no transitional model is needed in addition to the fully turbulent RANS models. The main geometrical parameters are presented in Table 1 (Zambonini, 2016).

Table 1 Geometrical parameters

\begin{tabular}{cc}
\hline \hline Parameter & Value \\
\hline Blade chord $c(\mathrm{~mm})$ & 150.0 \\
Blade axial chord $c_{x}(\mathrm{~mm})$ & 110.0 \\
Blade aspect ratio $h / c$ & 2.47 \\
Pitch to chord ratio $s / c$ & 0.893 \\
Blade camber angle $\varphi\left(^{\circ}\right)$ & 23.22 \\
Blade stagger angle $\gamma\left({ }^{\circ}\right)$ & 42.7 \\
Blade inlet angle $\beta_{1}\left({ }^{\circ}\right)$ & 54.31 \\
\hline
\end{tabular}

\section{Mesh}

The computational domain for the NACA65 cascade is shown in Fig. 1. The inlet plane is located at $2.16 c_{x}$ in the axial direction upstream of the leading edge, the same as the location of hot-wire measurements of the incoming endwall boundary layer (Ma, 2011; Zambonini, 2016). The outlet plane is placed at $1.36 c_{x}$ in the axial direction downstream of the trailing edge, the same as the location of the outlet of cascade test rig.

As the pitchwise periodicity of the time-mean flow was ensured throughout the measurement process (Ma, 2011), one single blade passage is simulated, with the pitchwise boundaries set as translational periodicity. Furthermore, as the surface oil flow measurements indicate the flow symmetry with respect to the mid-span (Ma, 2011), one half of the blade span is simulated, with the mid-span boundary set as symmetry.

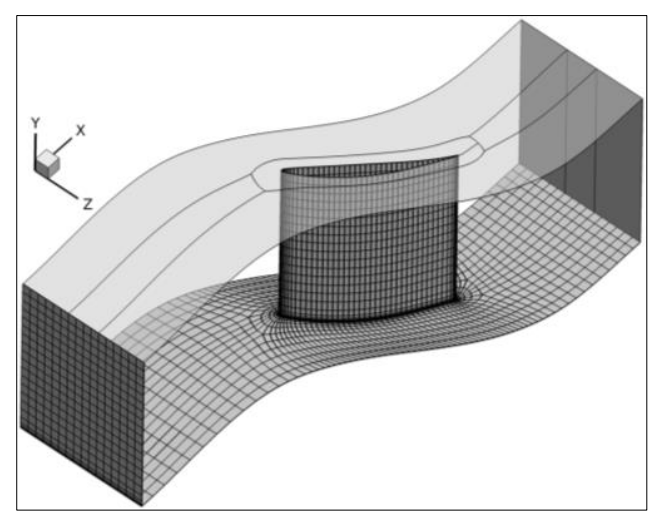

Figure 1: Computational domain (1 every 4 grid points shown for visual clarity)
An $\mathrm{O} 4 \mathrm{H}$ mesh topology is used, and hexahedral meshes are generated using NUMECA Autogrid ${ }^{v 5} .376$ points are wrapped around the blade and in the near-wall region above the blade surface, 37 points are distributed in the wall-normal direction, with the maximum $y^{+}$around 1.0 and near-wall grid expansion ratio 1.1. In the spanwise direction, 97 points are distributed, with the maximum $y^{+}$around 1.0 and nearwall grid expansion ratio 1.1 as well. Overall, the resulting mesh consists of about 2.9 million hexahedral cells.

\section{Boundary Conditions}

As for the mean-flow boundary conditions, the inlet mean velocity distribution, inlet flow angle, density, static temperature, and the outlet mean static pressure are prescribed to match the experimental measurements. At inlet, the velocity profile is specified based on a precursor RANS simulation on a zero pressure-gradient flat-plate turbulent boundary layer, with the results of which matching the single hotwire measurements of the cascade incoming endwall boundary layer. Figure 2 compares the inflow velocity profile generated by the authors with those provided by Ottawy's group (Zambonini, 2016). The computed results almost reproduce the experimental inflow measurements. The experimental flow parameters are listed in Tab. 2 (Zambonini, 2016).

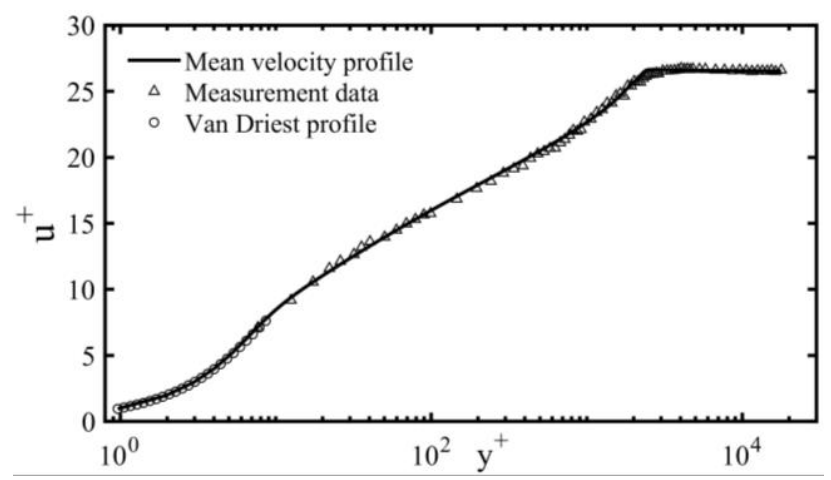

Figure 2: Inflow velocity profile in logarithmic plot

Table 2 Inlet flow parameters

\begin{tabular}{cc}
\hline \hline Parameter & Value \\
\hline $\begin{array}{c}\text { Chord-based Reynolds number, } R e_{c} \\
\text { Inlet freestream Mach number, } M\end{array}$ & $3.82 \times 10^{5}$ \\
$\begin{array}{c}\text { Non-dimensional inlet endwall boundary } \\
\text { layer thickness, } \delta_{1} / h\end{array}$ & 0.12 \\
$\begin{array}{c}\text { Inlet endwall boundary layer momentum } \\
\text { thickness, } \operatorname{Re}_{\theta}\end{array}$ & $71.11 \times 10^{-2}$ \\
$\quad \begin{array}{c}\text { factor, } H \\
\text { Inlet endwall boundary layer shape }\end{array}$ & 1.32 \\
$\quad \begin{array}{c}\text { Inlet incidence angle, } i\left(^{\circ}\right) \\
\text { Inlet freestream turbulence intensity, } T u\end{array}$ & 0,2 \\
\hline \hline
\end{tabular}

As for the inlet turbulence specification, no detailed hotwire measurements of the fluctuating velocities within the endwall boundary layer are available. Some uncertainties thus inevitably exist on the treatment of the inflow turbulence boundary conditions. In the current study, a uniform value of the turbulence quantities, $T u$ and the turbulence length scale $L_{t}$, are specified at inlet. $L_{t}$ is set as 
$\kappa \delta_{1}$, with the von Kármán constant $\kappa$ equal to 0.41 (Kármán, 1930). Here, it is noted that the turbulence-length-scale setting is plausible, as the inlet endwall boundary layer is fully turbulent $(H=1.32)$. For the $k$ - $\omega$ model, the turbulence kinetic energy $k$ is estimated from $T u$ and $U_{\infty}$, and the specific dissipation rate $\omega$ is determined by $k$ and $L_{t}$.

\section{RESULTS AND DISCUSSION}

\section{Model Validation}

Two flow cases for the LMFA-NACA65 compressor cascade are computed and discussed. The purpose of these computations is to confirm that compared with the BSL-2003 model with Boussinesq constitutive relation (BSL-2003-L), BSL-2003 with the above-mentioned non-linear stress-strain constitutive relation (BSL-2003-NL) can yield better predictions for the extent of corner separation at various inflow conditions.

\section{CASE $1\left(i=0^{\circ}\right)$}

Figure 3 compares the computed surface limiting streamlines distribution on the blade suction surface and the endwall by the BSL-2003-L and BSL-2003-NL models at the design flow condition. As shown on the endwall, the endwall boundary layer predicted by BSL-2003-NL exhibits stronger resistance to the adverse pressure gradient when migrating to the blade suction surface, thus leading to the smaller size of corner separation and delayed onset of separation location. On the blade suction surface, the size of corner separation predicted by BSL-2003-NL is also shown to be smaller in the chordwise direction than that by the BSL model with the linear Reynolds-stress closure. This confirms that the addition of the anisotropic effect of turbulence in the corner region acts to suppress the overprediction of corner separation.
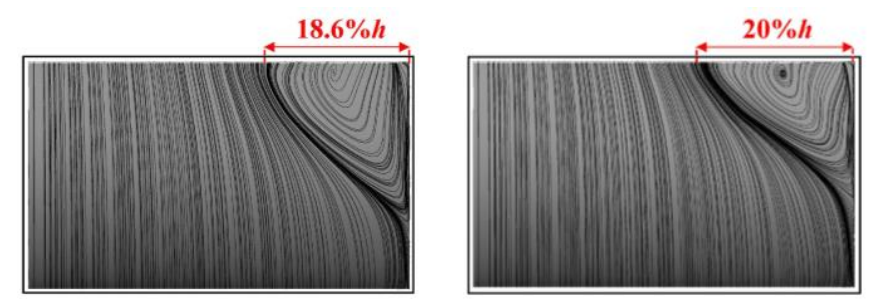

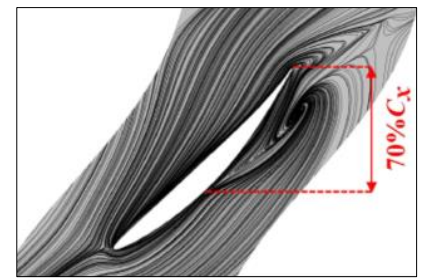

a) BSL-2003-L

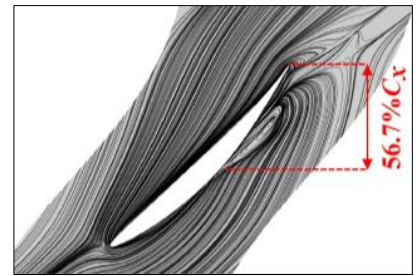

b) BSL-2003-NL
Figure 3: Surface flow visualization

To see how the overpredicted blockage affects the loading, Figure 4 presents the distributions of static pressure coefficient $C_{p s}$ on the blade surface. As Fig. 4a to $4 \mathrm{~b}$ shows, above the endwall separation region (above 20\% $h$ ), no separation occurs on the blade surface, and the blade loading predicted by both models matches closely with measurements. This indicates that the spanwise extent of corner separation does not exceed $20 \%$ of the blade span. Furthermore, the original BSL-2003 model predicts the pressure loading a bit lower than measurements on the pressure surface, which indicates a larger corner separation predicted in the pitchwise direction (see also in Fig. 3). Due to the larger passage blockage predicted, more flow is pushed towards the pressure surface, leading to the pressure reduced on the pressure surface due to increased velocity.

In the endwall separation region, the original BSL-2003 model predicts premature corner separation, while the BSL2003 model with the non-linear Reynolds-stress closure almost reflects the real flow field. As seen in Fig. 4c and 4d, the BSL-2003-L model results in the early boundary-layer separation on the suction surface. In contrast, a better pressure recovery is achieved by BSL-2003-NL in the rear part of the suction surface, which matches closely with the experimental measurements. However, in the region closest to the endwall $(2.7 \% h)$, the BSL-2003-L model results in the overprediction of both the streamwise and pitchwise extent of corner separation, while the BSL-2003-NL model gives results that are close to measurements. This indicates that the corner separation size could be predicted with good accuracy if the anisotropic properties of the flow in the corner region are reasonably modelled.

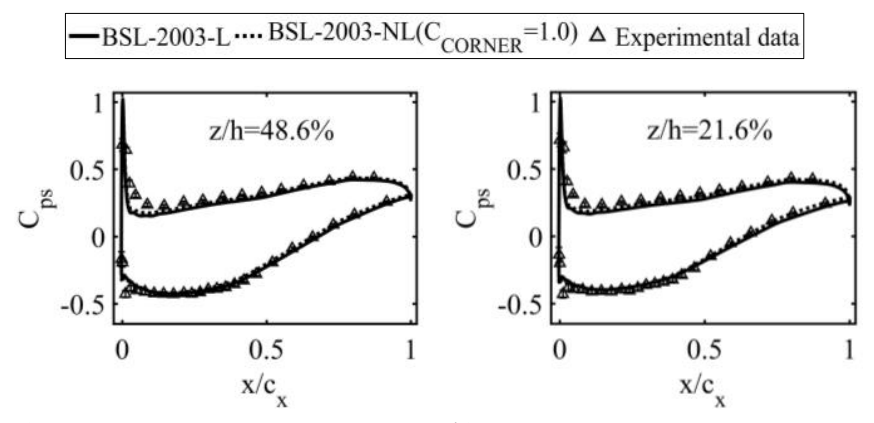

a)

b)
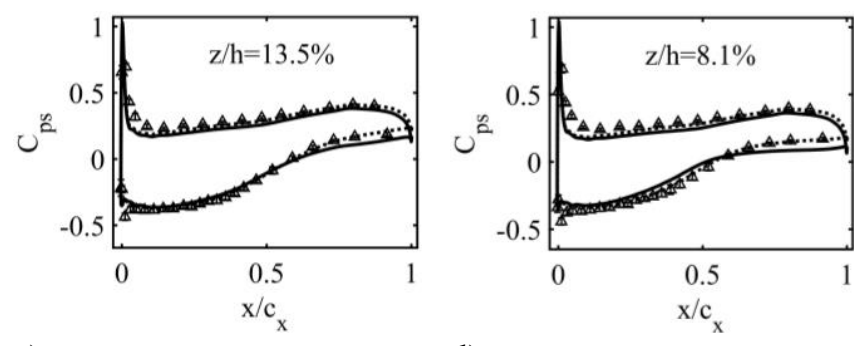

d)

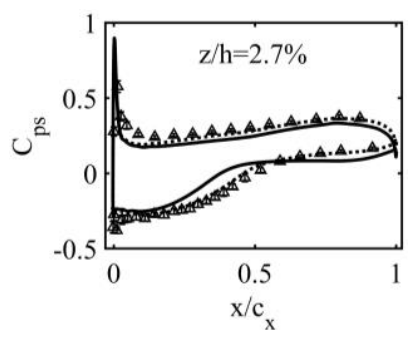

e)

Figure 4: Blade spanwise $C_{p s}$ distributions

Overall, it is encouraging to see that the prediction 
results for corner separation are quite promising, which means that some of the corner separation physics have been reasonably captured by the addition of the quadratic strainvorticity term to the Boussinesq constitutive relation.

Next, a more challenging test case will be presented to highlight the generality of this non-linear correction for corner separation flows.

\section{CASE $2\left(i=2^{\circ}\right)$}

At the off-design condition, a similar trend is seen for the shrink of the extent of corner separation in the chordwise and pitchwise directions (see also in Fig. 3). However, the spanwise extent of corner separation turns to be larger than that predicted by the original BSL model. This is caused by the increased spanwise velocity near the blade suction surface within the separation region, which is the resulting effect of the reconstruction of Reynolds stresses in the spanwise momentum transport equation.
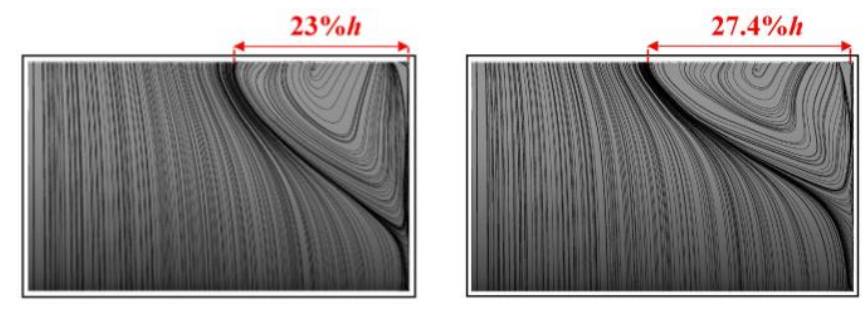

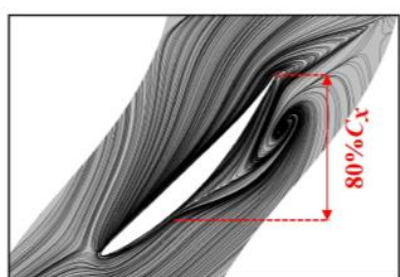

a) BSL-2003-L

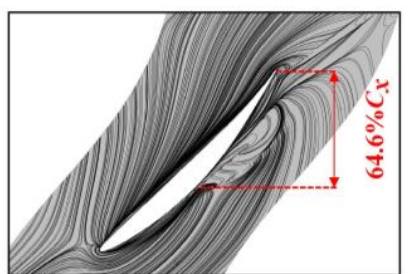

b) BSL-2003-NL
Figure 5: Surface flow visualization

Figure 6 shows the effect of the predicted corner separation on blade loading. In the region above the endwall separation (above $27 \% h$ ), the blade loading predicted by both models matches closely with measurements. However, moving down into the endwall separation region, as shown in Fig. 6c, a "pressure plateau" from $0.6 c_{x}$ towards the trailing edge was predicted by BSL-2003-L, indicating an overly large corner separation in the streamwise direction $\left(0.06 c_{x}\right.$ larger than measurements). In contrast, a pressure recovery that closely matches the measurements was predicted by BSL-2003-NL at $13.5 \% h$. Furthermore, as seen from Fig. 6d, the BSL-2003-NL model significantly improves the predictions of the separation onset on the blade surface, and the blade loading near the endwall region. This indicates that a significantly improved prediction of the chordwise and pitchwise extent of corner separation can be achieved by enhancement of the turbulence anisotropy in the endwall flow. This can be achieved by a simple non-linear expansion of the Boussinesq eddy-viscosity hypothesis.

However, in the region closest to the endwall (see in Fig. 6e), BSL-2003-NL predicts the corner separation onset earlier than measurements. The physical reason may partly be attributed to the underestimation of the anisotropic effects of turbulence in the corner separation by the non-linear stress-strain relation. As explained in the section "model formulation", $C_{C O R N E R}$ controls the strength of anisotropy in the normal stresses. The default value $C_{C O R N E R}=1.0$ was calibrated in the outer region of a simple wall boundary layer by requiring a fair level of anisotropy $\overline{(u)^{2}}>\overline{\left(w^{\prime}\right)^{2}}>\overline{\left(v^{\prime}\right)^{2}}$. Here, it shall be pointed out that the chosen $C_{C O R N E R}$ value is preliminary for $3 \mathrm{D}$ separated flows. It would be beneficial if systematic optimization of $C_{C O R N E R}$ be carried out based on the high-fidelity large eddy simulation (LES) results of this cascade at different inlet flow conditions, if available.

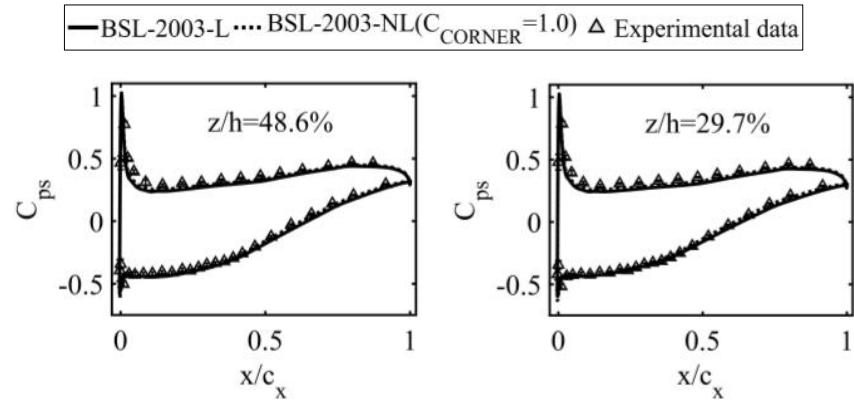

a)

b)
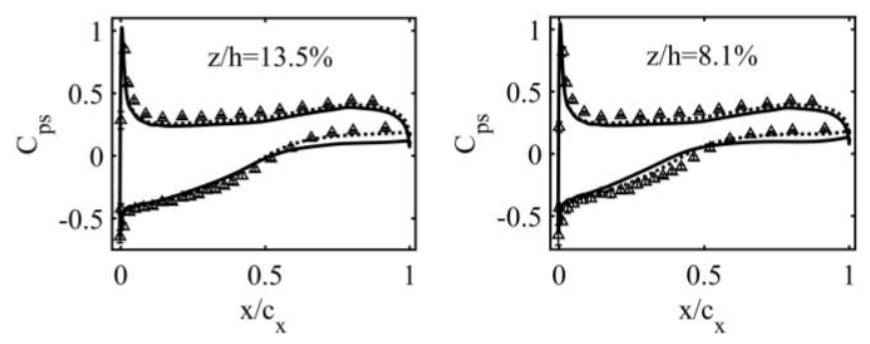

d)

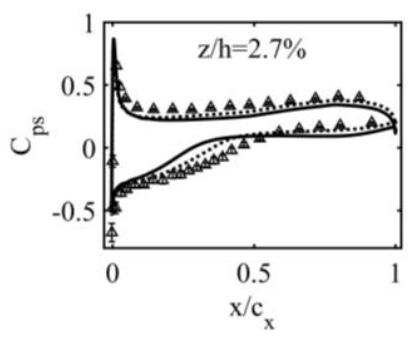

e)

Figure 6: Blade spanwise $C_{p s}$ distributions

In the next section, the flow field around the corner region will be analysed to reveal the effect of the anisotropic modification on the mean flow field.

\section{Flow Field Analysis}

Figure 7 compares the size of corner separation via the distribution of the eddy-to-molecular viscosity ratio $\left(v_{t} / v\right)$ around the trailing edge. The cut plane is placed just downstream of the blade trailing edge $\left(x=1.01 c_{x}\right)$ and is normal to the tangential direction of the blade camber line at the trailing edge. At the design flow condition, the original linear turbulence closure predicts larger corner separation than the quadratic turbulence closure does, with the turbulence intensity core (maximum turbulence intensity) for both being centred around $9.4 \%$ chord and $7.54 \%$ chord from 
the blade suction surface, respectively. Similar trend can be seen in the case $i=2^{\circ}$, and the results are not shown here due to space limitations.

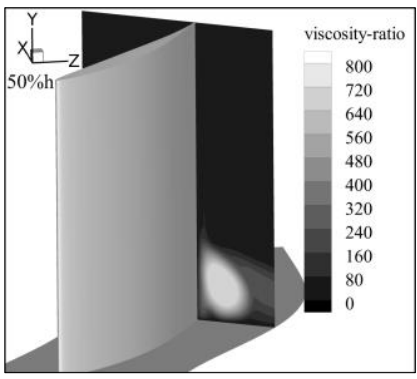

a) BSL-2003-L

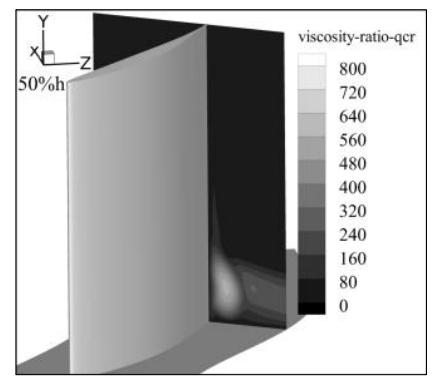

b) BSL-2003-NL
Figure 7: Comparison of the eddy-to-molecular viscosity ratio $\left(i=0^{\circ}\right)$

In order to more intuitively compare the mean vorticity field and Reynolds stress field below, a local coordinate system is setup with its three axes $s, y$, and $n$ respectively representing the streamwise, blade-spanwise, and bladesurface-normal directions (see in Fig. 8). The velocity vector, vorticity vector and the Reynolds stress tensor that are computed in the Cartesian coordinate system are projected onto the new local coordinate system.

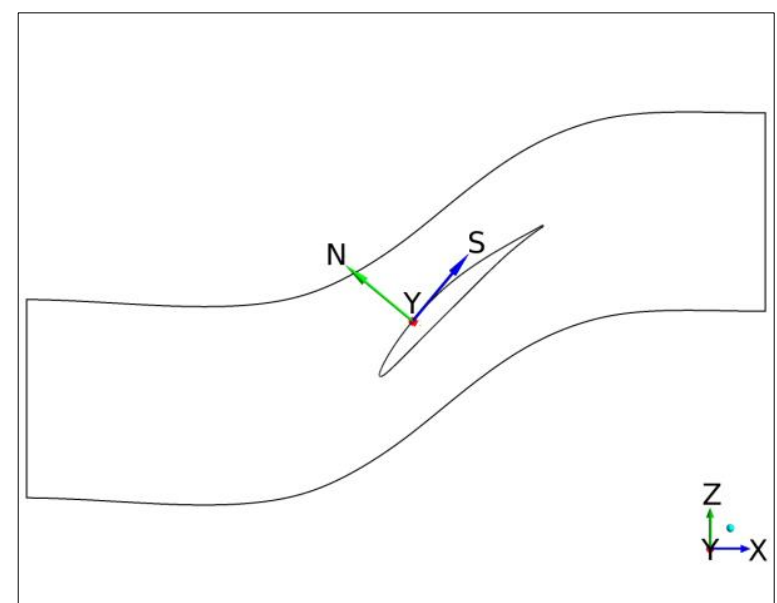

Figure 8: Notation for the $\boldsymbol{s} \boldsymbol{y} \boldsymbol{y}-\boldsymbol{n}$ local coordinate system

The generation of vortices in the corner can be described with the use of the streamwise ( $s$ axis) vorticity transport equation. With the assumption of incompressible and steady, this equation can be written as (Perkins, 1970):

$\bar{u}_{s} \frac{\partial \varepsilon}{\partial s}+\bar{u}_{n} \frac{\partial \varepsilon}{\partial n}+\bar{u}_{y} \frac{\partial \varepsilon}{\partial y}=\nu \nabla^{2} \varepsilon+\varepsilon \frac{\partial \bar{u}_{s}}{\partial s}+\eta \frac{\partial \bar{u}_{s}}{\partial n}+\zeta \frac{\partial \bar{u}_{s}}{\partial y}+\frac{\partial}{\partial s}\left(\frac{\partial\left\langle u_{s}^{\prime} u_{y}^{\prime}\right\rangle}{\partial n}-\right.$

$\left.\frac{\partial\left\langle u_{s}^{\prime} u_{n}^{\prime}\right\rangle}{\partial y}\right)+\frac{\partial^{2}}{\partial n \partial y}\left(\left\langle u_{y}^{\prime} u_{y}^{\prime}\right\rangle-\left\langle u_{n}^{\prime} u_{n}^{\prime}\right\rangle\right)+\left(\frac{\partial^{2}}{\partial n^{2}}-\frac{\partial^{2}}{\partial y^{2}}\right)\left\langle u_{n}^{\prime} u_{y}^{\prime}\right\rangle$

where $(\varepsilon, \eta, \zeta)^{T}$ denotes the vorticity components in the local streamwise, wall-normal, and spanwise directions. $\left(\bar{u}_{s}\right.$, $\left.\bar{u}_{n}, \bar{u}_{y}\right)^{T}$ and $\left(u_{s}^{\prime}, u_{n}^{\prime}, u_{y}^{\prime}\right)^{T}$ denote the Reynolds averaged velocity and Reynolds fluctuating components of velocity, respectively. In the right-hand side, let $P_{1}, P_{2}, P_{3}, P_{4}$ denote each part as:

$$
P_{1}=\varepsilon \frac{\partial \bar{u}_{s}}{\partial s}+\eta \frac{\partial \bar{u}_{s}}{\partial n}+\zeta \frac{\partial \bar{u}_{s}}{\partial y}
$$

$$
\begin{gathered}
P_{2}=\frac{\partial}{\partial s}\left(\frac{\partial\left\langle u_{s}^{\prime} u_{y}^{\prime}\right\rangle}{\partial n}-\frac{\partial\left\langle u_{s}^{\prime} u_{n}^{\prime}\right\rangle}{\partial y}\right) \\
P_{3}=\frac{\partial^{2}}{\partial n \partial y}\left(\left\langle u_{y}^{\prime} u_{y}^{\prime}\right\rangle-\left\langle u_{n}^{\prime} u_{n}^{\prime}\right\rangle\right) \\
P_{4}=\left(\frac{\partial^{2}}{\partial n^{2}}-\frac{\partial^{2}}{\partial y^{2}}\right)\left\langle u_{n}^{\prime} u_{y}^{\prime}\right\rangle
\end{gathered}
$$

According to Perkins, $P_{1}$ describes the production of streamwise vorticity through the deflexion, or shewing, of the mean shear by a transverse pressure gradient and/or body force, $P_{2}$ the production by primary shear stresses, $P_{3}$ the production by normal stress anisotropy, $P_{4}$ the production by secondary shear stress, and overall $P_{2}+P_{3}+P_{4}$ represents the production of vorticity by Reynolds stress gradients. For detailed expressions of each source term on the new local coordinate system $s-y-n$, see the Appendix.

In the discussions below, the effect of the explicit anisotropic modification on the mean vorticity field is first demonstrated by checking the streamwise vorticity source terms $P_{1}, P_{2}, P_{3}, P_{4}$, and the streamwise vorticity distribution upstream of the corner separation origin.

Figure 9 shows one selected cut plane that is normal to the blade camber line, i.e., $40 \% c_{x}$ (just upstream of the separation origin). The contour plots of vorticity and vorticity source terms $P_{1}, P_{2}, P_{3}$, and $P_{4}$ are shown on these planes to illustrate the effect of the anisotropic modification on the generation of streamwise vortices in the corner region.

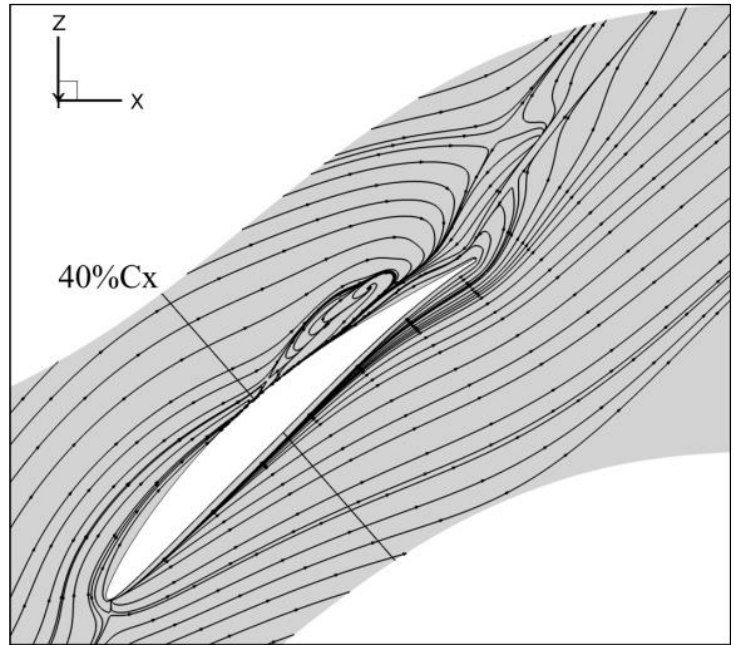

Figure 9: Endwall surface friction lines, BSL-2003-NL, $i=0^{\circ}$, with location of cut-plane normal to the blade camber line

Figure 10 shows the distribution of $P_{1}$ change caused by the anisotropic modification of Reynolds stresses, i.e. $\left(\left(P_{1}\right)_{N E V}\right)$. The given anisotropic modification results in the generation of counter-rotating corner vortices around the corner. This is understandable as based on the RANS governing equations, the mean flow field is determined by the way the Reynolds stresses are modelled. This means that the change in $P_{1}$ is a resulting effect of the change in 
Reynolds stresses by the anisotropic modification given in this paper. Judging from the rotation direction of the corner vortices, higher-momentum fluid in the main passage flow is entrained into the corner area, making the corner flow more resistant to the adverse pressure gradient and delaying the onset of corner separation.

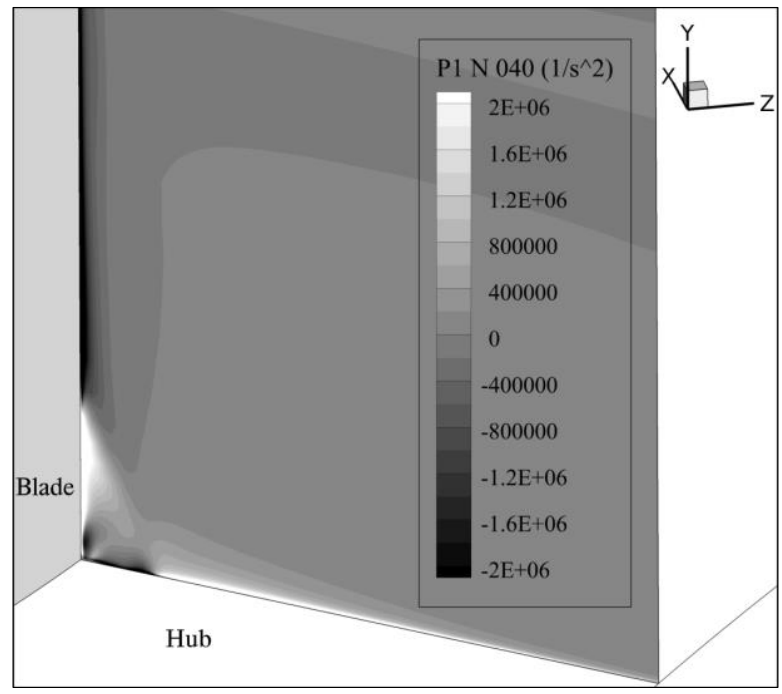

Figure 10: The net streamwise vorticity source term $\left(P_{1}\right)_{N E V}$ at $\left.40 \% c_{x}(i=0)^{\circ}\right)$

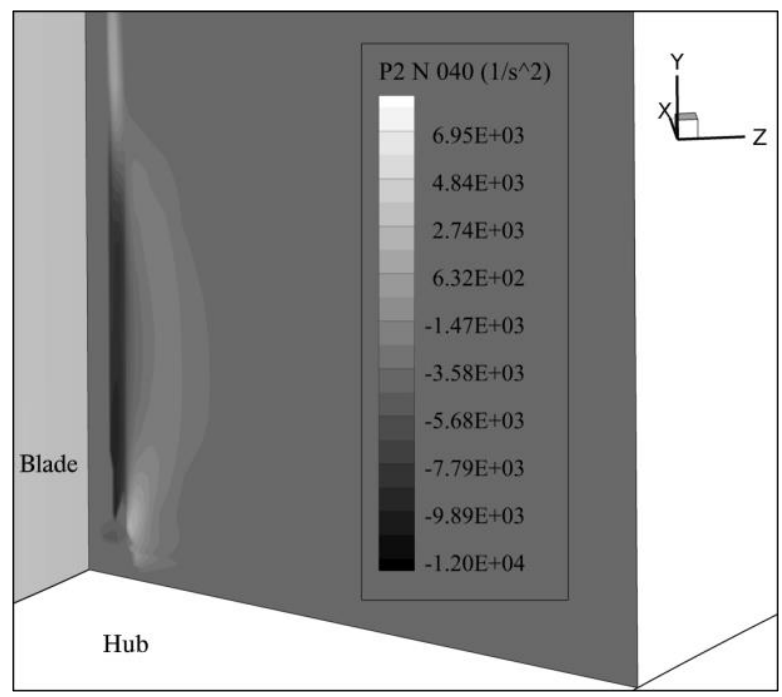

Figure 11: The non-linear part of the streamwise vorticity source term $\left(P_{2}\right)_{N E V}$ at $40 \% c_{x}\left(i=0^{\circ}\right)$

Figure 11 to 13 show the distributions of the non-linear part of the source terms $\left(P_{2}\right)_{N E V},\left(P_{3}\right)_{N E V},\left(P_{4}\right)_{N E V}$ on the cut plane $40 \% c_{x}$, respectively. The linear part $\left(P_{2}\right)_{E V}$, $\left(P_{3}\right)_{E V},\left(P_{4}\right)_{E V}$ and the non-linear part $\left(P_{2}\right)_{N E V},\left(P_{3}\right)_{N E V}$, $\left(P_{4}\right)_{N E V}$ are computed based on the solution from the BSL2003-NL simulation. They are defined as the source terms $P_{2}, P_{3}$, and $P_{4}$ being solved by the linear and quadratic parts of the Reynolds stresses, respectively.

For example, the linear term $\left\langle u^{\prime} u^{\prime}\right\rangle_{E V}$ and the quadratic term $\left\langle u^{\prime} u^{\prime}\right\rangle_{N E V}$ of the axial normal stress $\left\langle u^{\prime} u^{\prime}\right\rangle$ are expressed as (see in equation (1) and (2)):

$$
\left\langle u^{\prime} u^{\prime}\right\rangle_{E V}=\frac{2}{3} k-2 v_{t} S_{11}
$$

$$
\begin{gathered}
\left\langle u^{\prime} u^{\prime}\right\rangle_{N E V}=\frac{1.2 v_{t}}{\max \left(0.3 \omega, \sqrt{0.5\left(S^{2}+\Omega^{2}\right)}\right)}\left(S_{1 k} \Omega_{k 1}-\Omega_{1 k} S_{k 1}\right) \\
\left\langle u^{\prime} u^{\prime}\right\rangle=\left\langle u^{\prime} u^{\prime}\right\rangle_{E V}+\left\langle u^{\prime} u^{\prime}\right\rangle_{N E V}
\end{gathered}
$$

Similarly, each component of the Reynolds stress tensor can be split into the linear and quadratic parts. The footnotes 1,2, 3 in the components of the strain/vorticity tensor denote the axial, spanwise, and pitchwise directions, respectively.

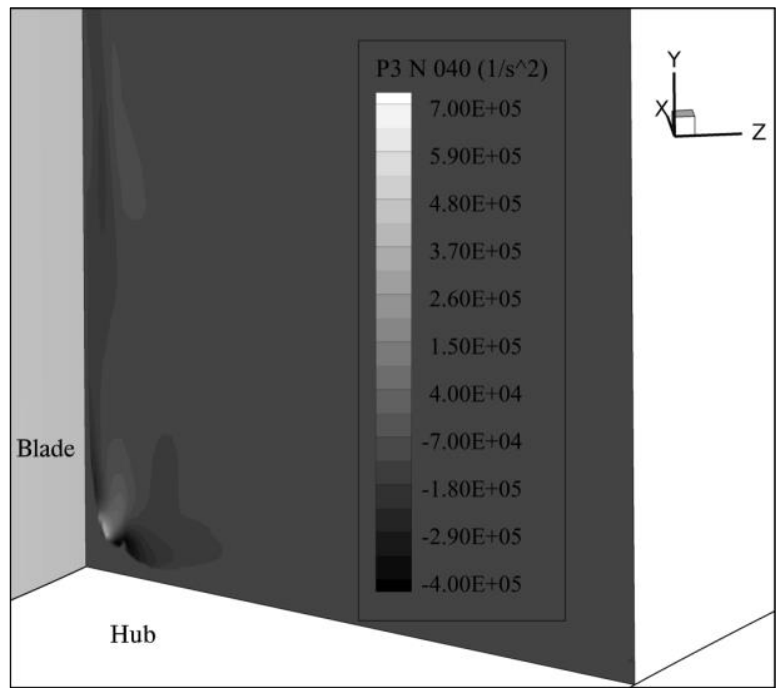

Figure 12: The non-linear part of the streamwise vorticity source term $\left(P_{3}\right)_{N E V}$ at $40 \% c_{x}\left(i=0{ }^{\circ}\right)$

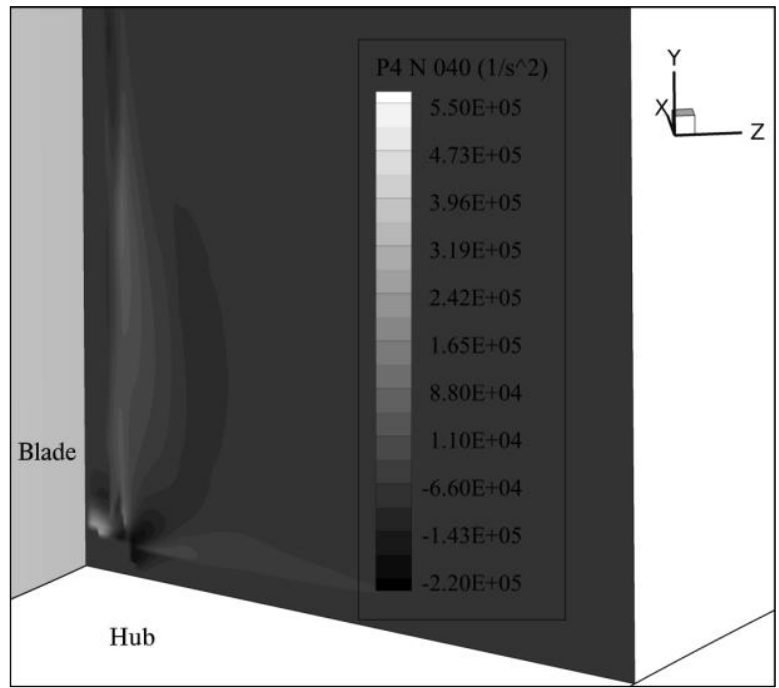

Figure 13: The non-linear part of the streamwise vorticity source term $\left(P_{4}\right)_{N E V}$ at $40 \% c_{x}\left(i=0^{\circ}\right)$

As seen in Fig 10 to 13, in the corner region just upstream of the origin of separation (see in Fig. 9), most of the streamwise vorticity production comes from $P_{1}, P_{3}$ and $P_{4}$, and those are of two orders of magnitude larger than that due to $P_{2}$. In Fig 10, 12 and 13, judging from the rotation direction of corner vortices, it can be concluded that the change in the skewing of the mean shear, the anisotropic modification of the normal stress anisotropy $\left\langle u_{y}^{\prime} u_{y}^{\prime}\right\rangle-\left\langle u_{n}^{\prime} u_{n}^{\prime}\right\rangle$ and the secondary shear stress $\left\langle u_{n}^{\prime} u_{y}^{\prime}\right\rangle$ contribute to the counter-rotating corner vortices produced in the corner region. 
Figure 14 and 15 show the effect of the explicit anisotropic modification on the streamwise vorticity distribution on the cut plane at $40 \% c_{x}$. The incorporation of higher-order terms in the stress-strain relation results in the generation of counter-rotating corner vortices. This is consistent with the distribution of streamwise vorticity source terms $P_{1}, P_{3}$ and $P_{4}$ at $40 \% c_{x}$ (see in Fig. 10, 12, and 13). Judging from the rotating direction of these two corner vortices, the higher-momentum fluid in the free space is entrained into the corner region, which energizes the corner flow and in turn delays the onset of separation.

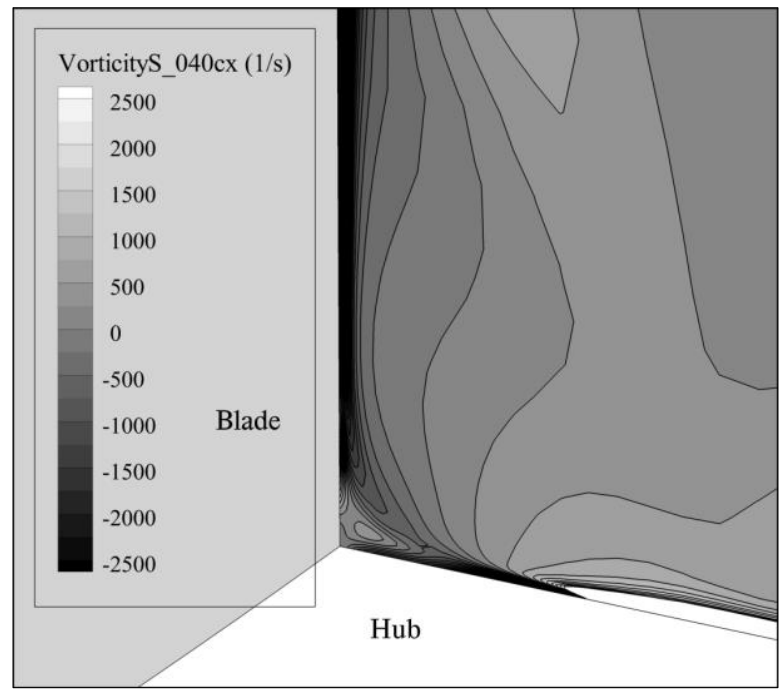

Figure 14: The streamwise vorticity at $40 \% c_{x}$, BSL2003-L, $i=0^{\circ}$

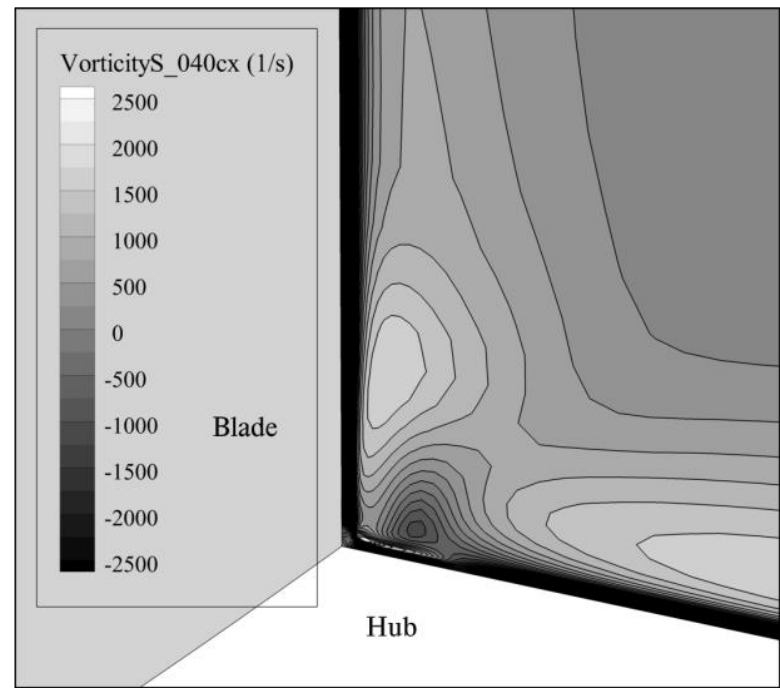

Figure 15: The streamwise vorticity at $40 \% c_{x}$, BSL2003-NL, $i=0^{\circ}$

This finding shows consistency with that from the external flow community (Yamamoto et al., 2012; Mani et al., 2013; Dandois, 2014). In the numerical study of the turbulent square-duct flow (Mani et al., 2013), secondary corner vortices were observed around the corner of the duct by replacement of the Boussinesq closure by the quadratic constitutive relation (Spalart 2000). The authors claimed that this is attributed to the capability of the quadratic constitutive relation to reproduce the physics of the normal stress anisotropy in the corner region, which leads to the appearance of corner vortices.

Next, the distributions of $P_{1}, P_{2}, P_{3}, P_{4}$ well within the corner separation are shown in relation to the flow behaviour within the corner separation region and within the separated shear layer between the main stream and the corner separation flow.

Figure 16 shows the selected cut plane, and again it is normal to the blade camber line, i.e. $68 \% c_{x}$. The contour plots of streamwise vorticity and vorticity source terms are shown on this plane to illustrate the effect of the anisotropic modification on the generation of streamwise vortices in the corner separation region.

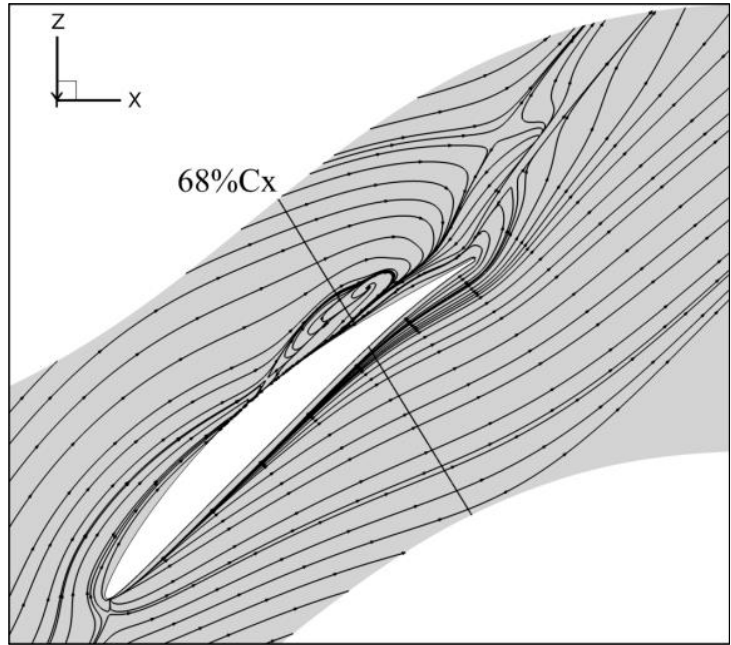

Figure 16: Endwall surface friction lines, BSL-2003-NL, $i=0^{\circ}$, with location of cut-plane normal to the blade camber line

Within the corner separation region $\left(68 \% c_{x}\right)$, as shown in Fig. 17 to 20, most of the streamwise vorticity production comes from $P_{1}, P_{3}$ and $P_{4}$. The contribution of the anisotropic modification of the primary shear stresses $\left\langle u_{s}^{\prime} u_{y}^{\prime}\right\rangle$, $\left\langle u_{s}^{\prime} u_{n}^{\prime}\right\rangle$ in the $P_{2}$ term to the streamwise vorticity production is significantly larger than that upstream of the corner separation region $\left(40 \% c_{x}\right)$ (see in Fig. 11). However, it is still significantly smaller compared to the other three terms.

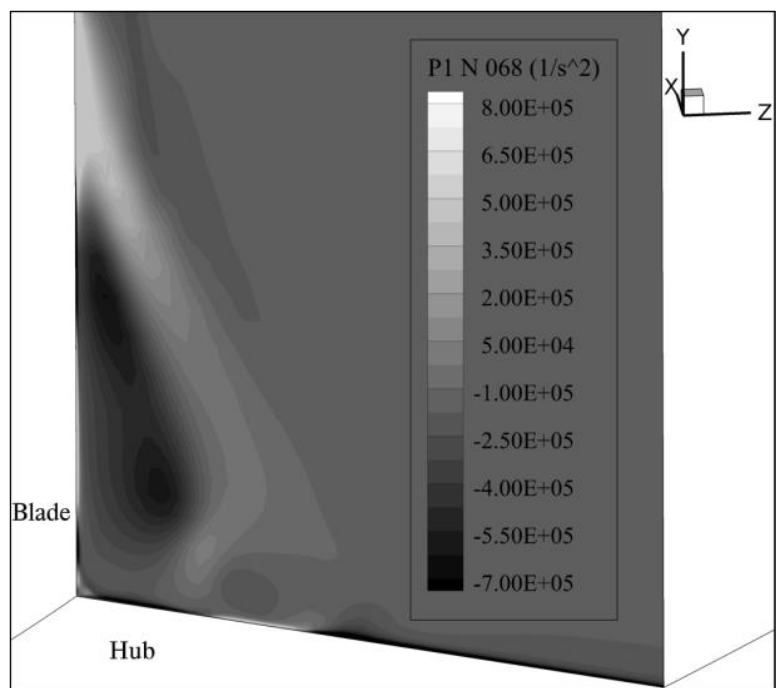

Figure 17: The non-linear part of the streamwise vorticity source term $\left(P_{1}\right)_{N E V}$ at $68 \% c_{x}\left(i=0^{\circ}\right)$ 
As seen in Fig. 17, the contribution of the mean shear skewing to the streamwise vorticity generation mainly concentrates in the separated shear layer between the corner separation region and the main flow where counter-rotating vortices coexist, which can enhance the turbulent shear between the corner separation region and the main flow. This contributes to stronger momentum exchange between the flow outside of the separation region and the corner separation flow, energizing the flow inside the corner separation and making it resistant to the bulk adverse pressure gradient.

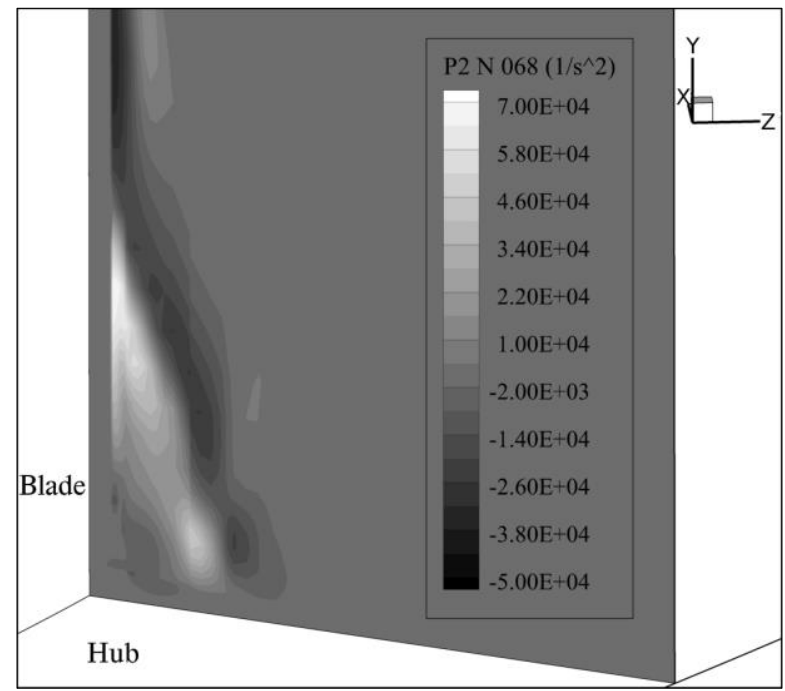

Figure 18: The non-linear part of the streamwise vorticity source term $\left(P_{2}\right)_{N E V}$ at $68 \% c_{x}\left(i=0^{\circ}\right)$

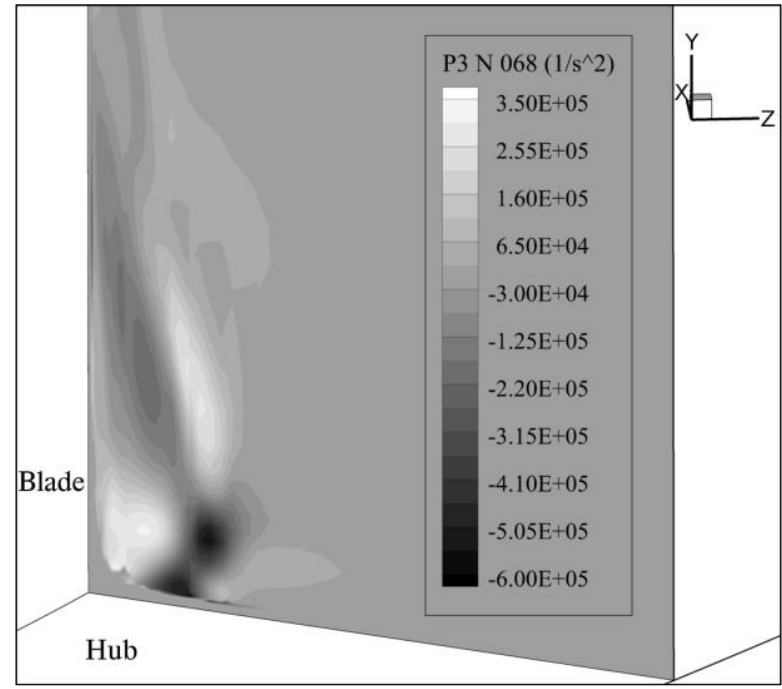

Figure 19: The non-linear part of the streamwise vorticity source term $\left(P_{3}\right)_{N E V}$ at $68 \% c_{x}\left(i=0^{\circ}\right)$

Similar trend can be seen in Fig. 19 and Fig. 20. The anisotropic modification of the normal stress anisotropy in $P_{3}$ and the secondary shear stress in $P_{4}$ leads to more and stronger streamwise vortices generated both along the outer part of the corner separation region and within the separation region. This indicates that strong shear shall exist both between the main flow and corner separation flow and within the separation region. Again, this leads to stronger momentum exchange between the main passage flow and the corner separation region, which energies the corner flow and makes it more resistant to separation.

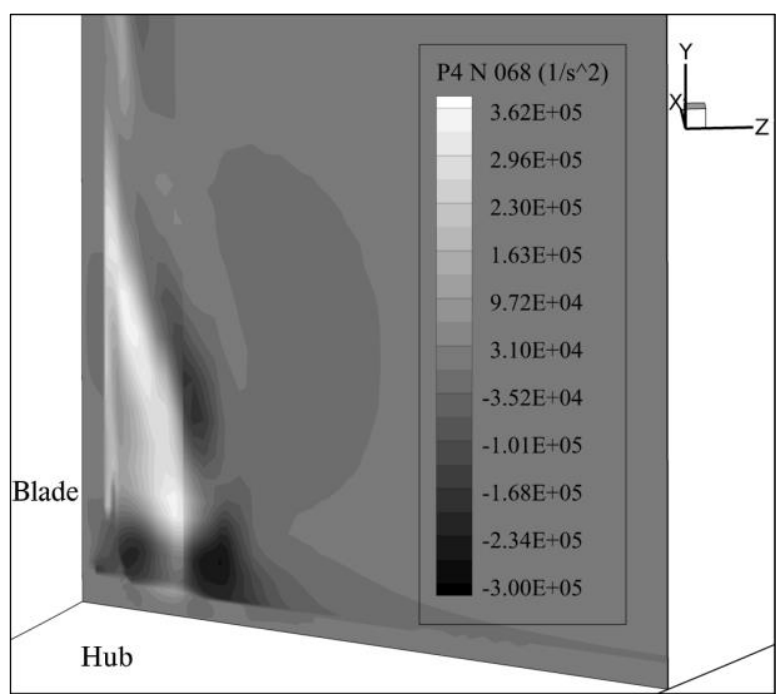

Figure 20: The non-linear part of the streamwise vorticity source term $\left(P_{4}\right)_{N E V}$ at $68 \% c_{x}\left(i=0^{\circ}\right)$

In summary, it can be clearly seen that the inclusion of Reynolds stress anisotropy contributes to an enhancement of the streamwise vorticities in the corner region. Next, the streamwise vorticity distributions are shown in Fig. 21 to 22 to illustrate the effect of the differences in the Reynolds stresses distributions on the streamwise vorticity field.
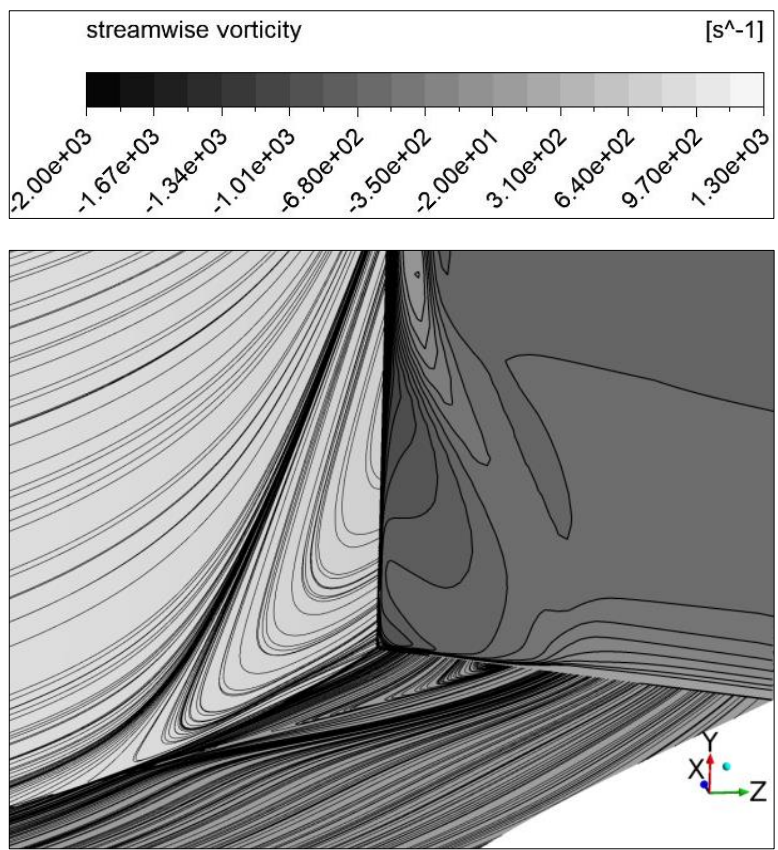

Figure 21: The streamwise vorticity at $68 \% c_{x}$, BSL2003-L, surface friction lines, $i=0^{\circ}$

Within the corner separation region, the contour lines of the streamwise vorticity predicted by the BSL-2003-NL model concentrate in the separated shear layer between the corner region and the main flow region that are close to the endwall (see in Fig. 22). This is consistent with the distribution of streamwise vorticity source terms $P_{3}$ and $P_{4}$ at $68 \% \mathrm{c}_{\mathrm{x}}$ (see in Fig. 19 and 20). This indicates that stronger shear interaction occurs in the separated shear layer 
between the main flow and the corner separation flow, and thus results in the higher-momentum fluid in the free space being entrained into the corner region. The corner flow is energized and in turn is more resistant to separation.
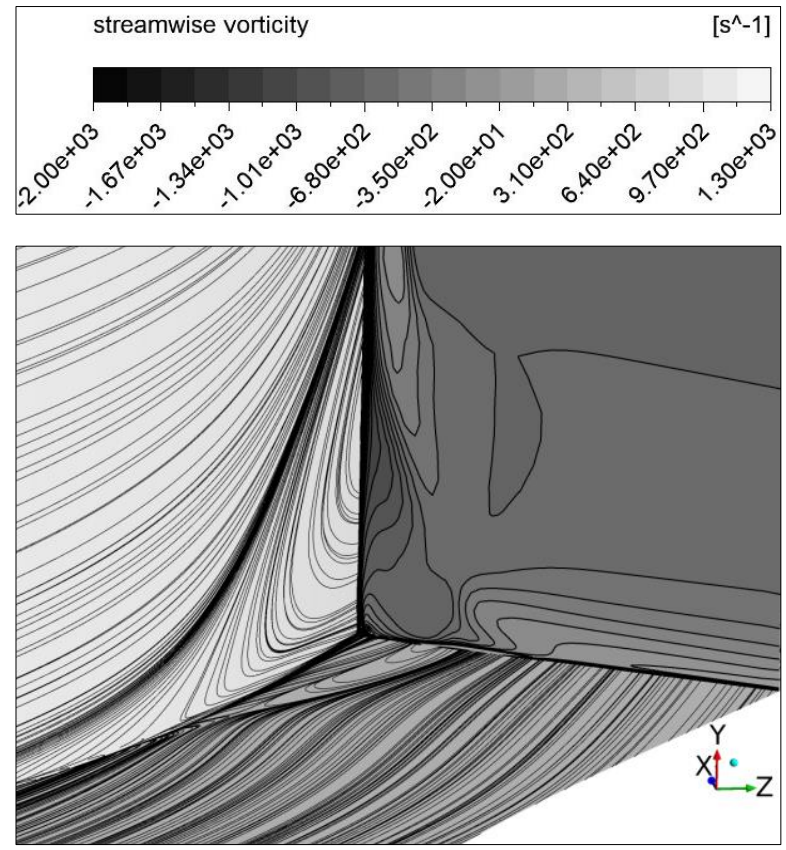

Figure 22: The streamwise vorticity at $68 \% c_{x}$, BSL2003-NL, surface friction lines, $i=0^{\circ}$

\section{CONCLUSIONS}

In the current study, a recently proposed quadratic stress-strain constitutive relation based on the $k-\omega$ type turbulence model has been used to numerically investigate the corner separation flows in the compressor blade passage. The following conclusions can be drawn from this study:

- In comparison with the original Boussinesq constitutive relation does, the non-linear, quadratic constitutive relation, when coupled with the Menter's hybrid $k-\omega / k-\varepsilon$ model, does give considerably better predictions for the extent of corner separation, at both design and off-design inflow conditions.

- One of the physical reasons for the improved predictive capabilities is that the inclusion of the quadratic strain-vorticity term to the Boussinesq Reynolds-stress closure increases the Reynolds stress anisotropy, which contributes to the counter-rotating corner vortices being generated in the corner region, and the higher turbulent shear stress within the separated shear layer. This can lead to more of the higher-momentum main flow being entrained into the corner region, in which the flow is energized and thus is more resistant to separation.

- The engineering concern for corner separation analysis is primarily to predict the blockage due to separation. Considering this, the non-linear explicit RANS closure shows its strong potential in determining the size of corner separation region with reasonable accuracy while maintains the low cost, numerical robustness, and convenience for implementation.

- However, as the inlet flow incidence increases, the size of corner separation becomes larger, and more significant discrepancies between the CFD results and experimental measurements are observed in terms of the blockage. In the current research phase, the authors have found that the extent of the numerical predicted corner separation is function of $C_{C O R N E R}$ as appeared in the quadratic strain-vorticity term. This calls for scale-resolving simulations in order to obtain understanding of the source of the anisotropy based on turbulence resolved simulation results. Further improvement of the current non-linear closure could be carried out based on the insight and understandings gained from further studies of the results of scaleresolving flow solutions.

\section{NOMENCLATURE}

$C_{p s} \quad$ static pressure coefficient, $\left(p-p_{1}\right) /\left(p_{01}-p_{1}\right)$

$i \quad$ inlet incidence angle, degree

$k \quad$ turbulence kinetic energy, $\mathrm{m}^{2} / \mathrm{s}^{2}$

$p \quad$ local static pressure, $\mathrm{Pa}$

$p_{1} \quad$ mean static pressure at inlet, $\mathrm{Pa}$

$p_{01} \quad$ freestream total pressure at inlet, $\mathrm{Pa}$

$u_{\tau} \quad$ wall-friction velocity, $\mathrm{m} / \mathrm{s}$

$u^{+} \quad$ non-dimensional mean velocity, $u / u_{\tau}$

$u^{\prime} \quad$ fluctuating velocity in the axial direction, $\mathrm{m} / \mathrm{s}$

$U_{\infty} \quad$ freestream velocity at inlet, $\mathrm{m} / \mathrm{s}$

$v \quad$ kinematic viscosity of the working fluid, $\mathrm{m}^{2} / \mathrm{s}$

$v^{\prime} \quad$ fluctuating velocity in the spanwise direction, $\mathrm{m} / \mathrm{s}$

$w^{\prime} \quad$ fluctuating velocity in the pitchwise direction, $\mathrm{m} / \mathrm{s}$

$y \quad$ wall-normal distance, $\mathrm{m}$

$y^{+} \quad$ non-dimensional wall-normal distance, $u_{\tau} y / v$

$\theta$ rotating angle between the local coordinate system $s-y-n$ and the Cartesian coordinate system $x-y-z$

$\langle\varphi\rangle \quad$ Reynolds average of $\varphi$

$\omega \quad$ specific dissipation rate, $1 / \mathrm{s}$

\section{SUBSCRIPTS}

ps static pressure

1 cascade inlet

$\infty \quad$ inlet freestream

EV linear term in the quadratic stress-strain constitutive relation

$N E V$ non-linear term in the quadratic stress-strain constitutive relation

\section{ACKNOWLEDGMENTS}

The authors would like to thank Prof. Xavier Ottavy of École Centrale de Lyon for providing the cascade geometry and part of the experimental data of LMFA-NACA65 compressor cascade. The authors would also like to thank Dr. Yu Xia of ANSYS UK Ltd for his technical service supports on the implementation of user-defined macros in FLUENT. 
Comments, questions and suggestions from anonymous reviewers are deeply appreciated.

\section{REFERENCES}

Boussinesq, J. (1903). Théorie analytique de la chaleur mise en harmonic avec la thermodynamique et avec la théorie mécanique de la lumière: Tome I-[II].. (Vol. 2). Gauthier-Villars.

Dandois, J. (2014). Improvement of Corner Flow Prediction Using the Quadratic Constitutive Relation. AIAA Journal, 52(12), pp. 2795-2806.

Dong, Y., Gallimore, S. J. and Hodson, H. P. (1986). Three-Dimensional Flows and Loss Reduction in Axial Compressors. In ASME 1986 International Gas Turbine Conference and Exhibit. American Society of Mechanical Engineers Digital Collection.

Gatski, T. B. and Speziale, C. G. (1993). On Explicit Algebraic Stress Models for Complex Turbulent Flows. Journal of Fluid Mechanics, 254, pp. 59-78.

Gbadebo, S. A., Cumpsty, N. A. and Hynes, T. P. (2005). Three-Dimensional Separations in Axial Compressors. J. Turbomach., 127(2), pp. 331-339.

Hanjalić, K. and Launder, B. E. (1976). Contribution

Towards a Reynolds-Stress Closure for Low-ReynoldsNumber Turbulence. Journal of Fluid Mechanics, 74(4), pp. 593-610.

Hellsten, A. and Wallin, S. (2009). Explicit Algebraic Reynolds Stress and Non-Linear Eddy-Viscosity Models. International Journal of Computational Fluid Dynamics, 23(4), pp. 349-361.

Liu, Y., Yan, H., Liu, Y., Lu, L. and Li, Q. (2016). Numerical Study of Corner Separation in a Linear Compressor Cascade Using Various Turbulence Models. Chinese Journal of Aeronautics, 29(3), pp. 639-652.

Ma, W., Ottavy, X., Lu, L., Leboeuf, F., and Gao, F. (2011). Experimental Investigations of Corner Stall in a Linear Compressor Cascade. Proceedings of the ASME 2011 Turbo Expo: Turbine Technical Conference and Exposition, 7, pp. 39-51.

Mani, M., Babcock, D., Winkler, C. and Spalart, P. (2013). Predictions of a Supersonic Turbulent Flow in a Square Duct. In 51 ${ }^{\text {st }}$ AIAA Aerospace Sciences Meeting Including the New Horizons Forum and Aerospace Exposition, pp. 860.

Menter, F. R. (1994). Two-Equation Eddy-Viscosity Turbulence Models for Engineering Applications. AIAA Journal, 32(8), pp. 1598-1605.

Menter, F. R., Kuntz, M. and Langtry, R. (2003). Ten Years of Industrial Experience with the SST Turbulence Model. Turbulence, heat and mass transfer, 4(1), pp. 625632.

Menter, F. R., Matyushenko, A. and Lechner, R. (2018). Development of a Generalized k- $\omega$ Two-Equation Turbulence Model. In Symposium der Deutsche Gesellschaft für Luft-und Raumfahrt, pp. 101-109.

Mishra, A. A. and Iaccarino, G. (2017). RANS Predictions for High-Speed Flows Using Enveloping Models. arXiv preprint arXiv:1704. 01699.
Monier, J. F., Gao, F., Boudet, J., Shao, L. and Lu, L. (2016). Budget Analysis of Turbulent Kinetic Energy in Corner Separation: RANS VS LES. In Proceedings of the European Conference on Computational Fluid Dynamics.

Perkins, H. J. (1970). The Formation of Streamwise Vorticity in Turbulent Flow. Journal of Fluid Mechanics, 44(4), pp.721-740.

Pope, S. B. (1975). A More General Effective-Viscosity Hypothesis. Journal of Fluid Mechanics, 72(2), pp. 331-340.

Spalart, P. R. and Allmaras, S. (1992). A One-Equation Turbulence Model for Aerodynamic Flows. In 30th Aerospace Sciences Meeting and Exhibit, pp. 439.

Spalart, P. R. (2000). Strategies for Turbulence Modelling and Simulations. International Journal of Heat and Fluid Flow, 21(3), pp. 252-263.

Spalart, P. R. (2015). Philosophies and Fallacies in Turbulence Modeling. Progress in Aerospace Sciences, 74, pp. 1-15.

Su, X. and Yuan, X. (2017). Improved Compressor Corner Separation Prediction Using the Quadratic Constitutive Relation. Proceedings of the Institution of Mechanical Engineers, Part A: Journal of Power and Energy, 231(7), pp. 618-630.

Von Kármán, T. (1930). Mechanische änlichkeit und turbulenz. Nachrichten von der Gesellschaft der Wissenschaften zu Göttingen, Mathematisch-Physikalische Klasse, pp. 58-76.

Wilcox, D. C. (1988). Reassessment of the ScaleDetermining Equation for Advanced Turbulence Models. AIAA Journal, 26(11), pp. 1299-1310.

Yamamoto, K., Tanaka, K. and Murayama, M. (2012). Effect of a Nonlinear Constitutive Relation for Turbulence Modeling on Predicting Flow Separation at Wing-Body Juncture of Transonic Commercial Aircraft. In 30th AIAA Applied Aerodynamics Conference, pp. 2895.

Zambonini, G., Ottavy, X. and Kriegseis, J. (2016). Corner Separation Dynamics in a Linear Compressor Cascade. In ASME Turbo Expo 2016: Turbomachinery Technical Conference and Exposition. American Society of Mechanical Engineers Digital Collection. 


\section{APPENDIX}

The source terms in the streamwise vorticity transport equations are expressed on the new local $s-y-n$ coordinate system (see in equations (12) to (15) and Fig. 8). These are obtained based on the Chain rule and the Galilean invariance, with detailed expressions listed below:

$$
\begin{aligned}
& P_{1}=\omega_{z} \frac{\partial \bar{u}_{z}}{\partial z} \cos ^{3} \theta+\omega_{y} \frac{\partial \bar{u}_{z}}{\partial z} \sin \theta \cos ^{2} \theta+\omega_{z} \frac{\partial \bar{u}_{y}}{\partial z} \sin \theta \cos ^{2} \theta \\
& +\omega_{y} \frac{\partial \bar{u}_{y}}{\partial z} \sin ^{2} \theta \cos \theta+\omega_{z} \frac{\partial \bar{u}_{z}}{\partial y} \sin \theta \cos ^{2} \theta+\omega_{y} \frac{\partial \bar{u}_{z}}{\partial y} \sin ^{2} \theta \cos \theta \\
& +\omega_{z} \frac{\partial \overline{u_{y}}}{\partial y} \sin ^{2} \theta \cos \theta+\omega_{y} \frac{\partial \overline{u_{y}}}{\partial y} \sin ^{3} \theta+\omega_{y} \frac{\partial \overline{u_{z}}}{\partial y} \cos ^{3} \theta \\
& -\omega_{z} \frac{\partial \bar{u}_{z}}{\partial y} \sin \theta \cos ^{2} \theta+\omega_{y} \frac{\partial \bar{u}_{y}}{\partial y} \sin \theta \cos ^{2} \theta-\omega_{z} \frac{\partial \bar{y}_{y}}{\partial y} \sin ^{2} \theta \cos \theta \\
& -\omega_{y} \frac{\partial \bar{u}_{z}}{\partial z} \sin \theta \cos ^{2} \theta+\omega_{z} \frac{\partial \overline{u_{z}}}{\partial z} \sin ^{2} \theta \cos \theta-\omega_{y} \frac{\partial \bar{u}_{y}}{\partial z} \sin ^{2} \theta \cos \theta \\
& +\omega_{z} \frac{\partial \bar{u}_{y}}{\partial z} \sin ^{3} \theta+\omega_{x} \frac{\partial \bar{u}_{z}}{\partial x} \cos \theta+\omega_{x} \frac{\partial \bar{u}_{y}}{\partial x} \sin \theta \\
& P_{2}=\sin ^{2} \theta \cos \theta \frac{\partial^{2}\left\langle u^{\prime} v^{\prime}\right\rangle}{\partial y^{2}}+\sin \theta \cos ^{2} \theta \frac{\partial^{2}\left\langle u^{\prime} w^{\prime}\right\rangle}{\partial y^{2}}-\sin ^{3} \theta \frac{\partial^{2}\left\langle u^{\prime} v^{\prime}\right\rangle}{\partial y \partial z} \\
& -\sin ^{2} \theta \cos \theta \frac{\partial^{2}\left\langle u^{\prime} w^{\prime}\right\rangle}{\partial y \partial z}+\sin \theta \cos ^{2} \theta \frac{\partial^{2}\left\langle u^{\prime} v^{\prime}\right\rangle}{\partial y \partial z}+\cos ^{3} \theta \frac{\partial^{2}\left\langle u^{\prime} w^{\prime}\right\rangle}{\partial y \partial z} \\
& -\sin ^{2} \theta \cos \theta \frac{\partial^{2}\left\langle u^{\prime} v^{\prime}\right\rangle}{\partial z^{2}}-\sin \theta \cos ^{2} \theta \frac{\partial^{2}\left\langle u^{\prime} w^{\prime}\right\rangle}{\partial z^{2}} \\
& -\sin ^{2} \theta \cos \theta \frac{\partial^{2}\left\langle v^{\prime} v^{\prime}\right\rangle}{\partial x \partial y}+\sin ^{3} \theta \frac{\partial^{2}\left\langle v^{\prime} w^{\prime}\right\rangle}{\partial x \partial y} \\
& -\sin \theta \cos ^{2} \theta \frac{\partial^{2}\left\langle v^{\prime} w^{\prime}\right\rangle}{\partial x \partial y}+\sin ^{2} \theta \cos \theta \frac{\partial^{2}\left\langle w^{\prime} w^{\prime}\right\rangle}{\partial x \partial y} \\
& -\sin \theta \cos ^{2} \theta \frac{\partial^{2}\left\langle v^{\prime} v^{\prime}\right\rangle}{\partial x \partial z}+\sin ^{2} \theta \cos \theta \frac{\partial^{2}\left\langle v^{\prime} w^{\prime}\right\rangle}{\partial x \partial z} \\
& -\cos ^{3} \theta \frac{\partial^{2}\left\langle v^{\prime} w^{\prime}\right\rangle}{\partial x \partial z}+\sin \theta \cos ^{2} \theta \frac{\partial^{2}\left\langle w^{\prime} w^{\prime}\right\rangle}{\partial x \partial z} \\
& P_{3}=\cos \theta \frac{\partial^{2}\left\langle u^{\prime} u^{\prime}\right\rangle}{\partial x \partial y}-\cos ^{3} \theta \frac{\partial^{2}\left\langle v^{\prime} v^{\prime}\right\rangle}{\partial x \partial y}+2 \sin \theta \cos ^{2} \theta \frac{\partial^{2}\left\langle v^{\prime} w^{\prime}\right\rangle}{\partial x \partial y} \\
& -\sin ^{2} \theta \cos \theta \frac{\partial^{2}\left\langle w^{\prime} w^{\prime}\right\rangle}{\partial x \partial y}-\sin \theta \frac{\partial^{2}\left\langle u^{\prime} u^{\prime}\right\rangle}{\partial x \partial z}+\sin \theta \cos ^{2} \theta \frac{\partial^{2}\left\langle v^{\prime} v^{\prime}\right\rangle}{\partial x \partial z} \\
& -2 \sin ^{2} \theta \cos \theta \frac{\partial^{2}\left\langle v^{\prime} w^{\prime}\right\rangle}{\partial x \partial z}+\sin ^{3} \theta \frac{\partial^{2}\left\langle w^{\prime} w^{\prime}\right\rangle}{\partial x \partial z} \\
& P_{4}=\cos ^{3} \theta \frac{\partial^{2}\left\langle u^{\prime} v^{\prime}\right\rangle}{\partial y^{2}}-2 \sin \theta \cos ^{2} \theta \frac{\partial^{2}\left\langle u^{\prime} v^{\prime}\right\rangle}{\partial y \partial z}+\sin ^{2} \theta \cos \theta \frac{\partial^{2}\left\langle u^{\prime} v^{\prime}\right\rangle}{\partial z^{2}} \\
& -\sin \theta \cos ^{2} \theta \frac{\partial^{2}\left\langle u^{\prime} w^{\prime}\right\rangle}{\partial y^{2}}+2 \sin ^{2} \theta \cos \theta \frac{\partial^{2}\left\langle u^{\prime} w^{\prime}\right\rangle}{\partial y \partial z}-\sin ^{3} \theta \frac{\partial^{2}\left\langle u^{\prime} w^{\prime}\right\rangle}{\partial z^{2}} \\
& -\cos \theta \frac{\partial^{2}\left\langle u^{\prime} v^{\prime}\right\rangle}{\partial x^{2}}+\sin \theta \frac{\partial^{2}\left\langle u^{\prime} w^{\prime}\right\rangle}{\partial x^{2}}
\end{aligned}
$$

where $\left(\omega_{x}, \omega_{y}, \omega_{z}\right)^{T}$ denotes the vorticity vector in Cartesian coordinates; $\theta$ is the angle between the $x-y-z$ coordinate system and the $s-y-n$ coordinate system in the anti-clockwise rotation direction. 